University of Nebraska - Lincoln

DigitalCommons@University of Nebraska - Lincoln

Roman L. Hruska U.S. Meat Animal Research

U.S. Department of Agriculture: Agricultural Center

Research Service, Lincoln, Nebraska

2013

Analysis of feeding behavior of group housed growing-finishing

pigs

T.M. Brown-Brandl

USDA-ARS-U.S. Meat Animal Research Center, Tami.BrownBrandl@ARS.USDA.GOV

G.A. Rohrer

USDA-ARS-U.S. Meat Animal Research Center, gary.rohrer@ars.usda.gov

R.A. Eigenberg

USDA-ARS-U.S. Meat Animal Research Center, roger.eigenberg@ars.usda.gov

Follow this and additional works at: https://digitalcommons.unl.edu/hruskareports

Brown-Brandl, T.M.; Rohrer, G.A.; and Eigenberg, R.A., "Analysis of feeding behavior of group housed growing-finishing pigs" (2013). Roman L. Hruska U.S. Meat Animal Research Center. 201. https://digitalcommons.unl.edu/hruskareports/201

This Article is brought to you for free and open access by the U.S. Department of Agriculture: Agricultural Research Service, Lincoln, Nebraska at DigitalCommons@University of Nebraska - Lincoln. It has been accepted for inclusion in Roman L. Hruska U.S. Meat Animal Research Center by an authorized administrator of DigitalCommons@University of Nebraska - Lincoln. 


\title{
Analysis of feeding behavior of group housed growing-finishing pigs
}

\author{
T.M. Brown-Brandl*, G.A. Rohrer, R.A. Eigenberg \\ USDA-ARS-MARC, Clay Center, NE, USA
}

\section{A R T I C L E I N F O}

\section{Article history:}

Received 12 December 2012

Received in revised form 4 May 2013

Accepted 8 June 2013

\section{Keywords: \\ Age \\ Animal density \\ Feeding behavior \\ Group housed pigs \\ Health \\ RFID}

\begin{abstract}
A B S T R A C T
Feeding behavior and time spent eating contains valuable information that can be used for managing livestock, identifying sick animals, and determining genetic differences within a herd. Individual animal feeding behavior, in a commercial-sized pen, was recorded using radio-frequency identification (RFID) technology and a series of multiplexers. Data were collected on 960 pigs (mixed barrows, 406 and gilts, 600 ) over 4 grow-out periods. The animals entered the facility at $24.6 \pm 5.4 \mathrm{~kg}$ (mean \pm standard deviation) at approximately 65 days of age and exited the facility at $101.4 \pm 13.8 \mathrm{~kg}$ (between 116 and 133 days later). Time spent at the feeder was analyzed for the effects of days on feed, sex, weight gain, and health effects. The amount of time spent at the feeder averaged $68.8 \mathrm{~min} \mathrm{day}^{-1}$ pig $^{-1}$ over the grow-out period, and increased from the day the pigs enter the facility $\left(24.0 \pm 1.6 \mathrm{~min} \mathrm{day}^{-1} \mathrm{pig}^{-1}\right.$; mean \pm standard error) until plateauing at approximately 40 days later $\left(76.7 \pm 2.4 \mathrm{~min} \mathrm{day}^{-1}\right.$ pig $^{-1}$; age $\sim 105$ days). After the plateau, barrows spent 13.6 more minutes per day at the feeder than gilts. Pigs classified as 'high gaining' (79.2 $\left.\pm 5.1 \mathrm{~min} \mathrm{day}^{-1} \mathrm{pig}^{-1}\right)$ spent more time at the feeder than pigs classified as either 'normal' (72.6 $\left.\pm 2.6 \mathrm{~min} \mathrm{day}^{-1} \mathrm{pig}^{-1}\right)$ or 'low gaining' $\left(67.6 \pm 5.3 \mathrm{~min} \mathrm{day}^{-1} \mathrm{pig}^{-1}\right)$. This initial manuscript demonstrates the potential of utilizing feeding behavior or time spent eating as a method of managing animals.
\end{abstract}

Published by Elsevier B.V.

\section{Introduction}

Feeding behavior contains important information that can enable producers to better manage livestock; similarly researchers can benefit by better understanding factors that influence feed intake. Feeding behavior in livestock species has been reported in many different studies (Bach et al., 2004; Bigelow and Houpt, 1988; Chapinal et al., 2007; Morgan et al., 2000; Nienaber et al., 1990, 1991). Each study includes various parameters of feeding behavior parameters that have included feed intake, meal (bout) length, meal (bout) interval, number of meals (bout) per day, total time spent eating, and rate of eating.

Systems are currently available to measure feed intake in association with feeding behavior for cattle (Basarab et al., 2003; Chapinal et al., 2007; Kelly et al., 2010), swine (Andree and Huegle, 2001; Chapinal et al., 2008; Hyun and Ellis, 2002; Nienaber et al., 1991), small livestock (Basarab et al., 2003; Gipson et al., 2006, 2007; Goetsch et al., 2010), and poultry (Puma et al., 2001). While some of these systems provide the user with feed intake data in addition to feeding behavior, they require feeders to be accessed by a single animal at a time and due to the cost only a limited

* Corresponding author. Address: U.S. Meat Animal Research Center, P.O. Box 166, Clay Center, NE, USA. Tel.: +1 (402) 762 4279; fax: +1 (402) 7624273.

E-mail addresses: tami.brownbrandl@ars.usda.gov (T.M. Brown-Brandl), gary.rohrer@ars.usda.gov (G.A. Rohrer), roger.eigenberg@ars.usda.gov (R.A. Eigenberg). number of feeding stations are placed in a pen. While, feed intake is a very important parameter in some studies (i.e. genetic evaluation, nutrition studies), it may not be necessary for others. Limited access to the feeder can alter the animal's behavior and maybe be representative commercial sized pens. In addition, to not altering feeding behavior, a system to monitor only feeding behavior has less equipment and no moving parts, therefore is less costly and easier to maintain. Therefore, systems that allow recording of feeding behavior (without feed intake) may be more applicable to production animal facilities. The parameters that could be measured in such a system would include meal (bout) length, meal (bout) interval, number of meals (bout) per day, and total time spent eating. Feed intake (kg/day) and rate of eating (g/min) are two parameters that could not be monitored in such a system.

Systems that record feeding behavior could provide a useful tool in managing production animals. Research has indicated that feed intake and feeding behavior changes can occur with relation to thermal conditions (Nienaber and Hahn, 2000), diet (Adijaoude et al., 2000; Fuller et al., 1995), social interactions (Goetsch et al., 2010), dominance ranking (Chapinal et al., 2008; Soltysiak and Ogalski, 2010; Val-Laillet et al., 2008; Walker et al., 2008), number of animals in a pen (Korthals, 2000), and health status (Griffin, 2001). Some research has worked to develop analysis methods for the process the feeding behavior data (Gates and Xin, 2008). However, most of these data were collected from small groups or individually housed animals. There is a need to investigate the dynamics of 
feeding behavior in livestock species within a commercial setting. With the continued improvement in instrumentation and better understanding of animals' responses, systems could possible be developed to electronically monitor animals ensure proper care of animals for improved well-being, for profitability of operations, and to ensure the correct use of antibiotics in our meat animals.

Objectives of this research were to describe the development of a system to record feeding behavior, then use the system to collect data to (1) determine how time spent eating varies with pig age, (2) quantify differences in time spent eating between barrows and gilts, (3) determine the impact of weight gain on time spent eating, and (4) evaluate the impact of health on time spent eating. The results of this data analysis will help assess the potential of utilizing feeding behavior to manage animals in a commercial setting.

\section{Materials and methods}

\subsection{Equipment}

A system to monitor feeding behavior in group-housed swine was developed and installed at the USMARC. The system utilizes radio-frequency identification (RFID) system and was designed around a commercial reader (Texas Instruments, Series 2000 High Performance Remote Antenna-Reader Frequency Module [RARFM][RI-RFM-008B-00]). This reader was designed to read low frequency half duplex electronic identification tags (EID) that were affixed to the animal. The radio-frequency signal was distributed to a series of antennas using a multiplexer (MPX) designed and constructed by the authors. Multiplexers were used for two different applications in the system: first to distribute the signal to various pens, and second to distribute the signal to various antennas within a single pen. The same multiplexer design was used in both applications.

Multiplexers were designed to function as multiple (eight switch locations) switches connecting the signal from the RARFM to the correct antenna. Fig. 1 shows a block diagram of a MPX; an input to the MPX can be directed to any of eight outputs with double pole switching. Multiplexer switching was controlled by a four-wire system: three control lines and a ground. The MPX control signal originated with the Series 2000 Control Module where control lines were latched under control of TFX-11 microcontrollers, Onset Computer Corp., 536 MacArthur Blvd., Pocasset, MA 02559, via RS232 communication. Multiplexer control switching was designed as a current loop, with a 0 or 4 milliamp signal representing 0 and 1 respectively. Current loop control was chosen for noise immunity over long wire runs. The control currents were used to drive LEDs in optical isolators, making the MPXs electrically isolated and immune to potential ground loops. Optical isolator boards were designed to couple the control lines that originated at the Series 2000 Control Board to the MPXs. The TFX-11 microcontroller sent a serial command to the Series 2000 Control Board, which latched the correct binary code for the correct feeder and the correct antenna within the feeder. Binary coded optically isolated lines distributed the signal to the MPXs, which latched the correct relays providing a pathway to and from the RA-RFM.

\subsection{Software}

The software was designed in two separate components. The first component was intended to function on the main computer and was designed for timing, data management, and display. The second component was intended to function on a micro-controller and was designed to control the sequence of the antennas and to capture one cycle of data. This approach was used for ease of expansion; multiple micro-controllers can be added to the system for larger installations.

The operational software for the PC host computer was written using HT Basic (HT Basic for Windows, Ver. 9.5. TransEra Corp., 375 East 800 South, Orem, UT 84097). The host system determined the timing of each scan (a sequence of powering each antenna and recording the EID number if present). This timing can be changed and was determined by the speed of the host computer; for this application a 20-s time base was used. After the host computer initiated the scan, it was available to summarize the number of hits

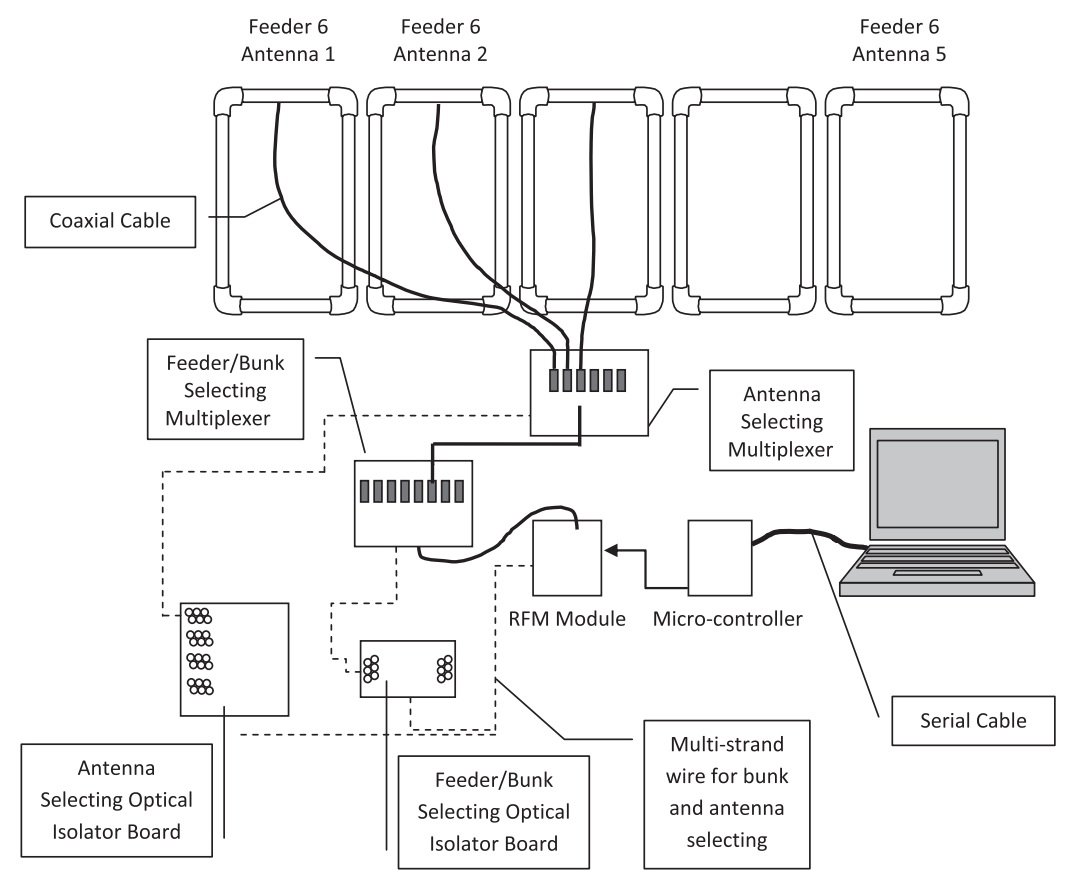

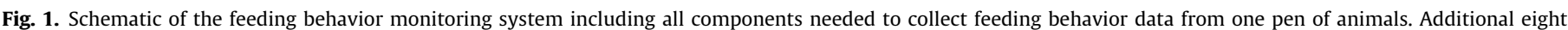

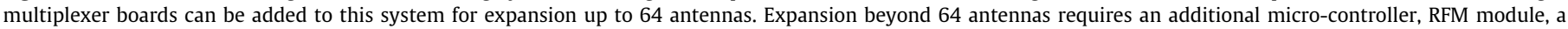
feeder selecting optical isolator board, an antenna selecting optical isolator board, feeder selecting multiplexer and a set of antenna selecting multiplexer boards. 
of each antenna or for each animal upon the user's request. At the end of the scan, the micro-controller sent an "end" statement to the host computer, which initiated a data dump from each micro-controller in sequence. The data were received and then written to the comma-delimited file; the appropriate information was transferred to the antenna and animal history files for ease of creating summaries. The host computer remained idle until the time to initiate the next scan.

The micro-controller, TFX-11 micro-controller, was programmed using TFBasic (TFTools, Ver. 1.1.1.4, Onset Computer Corp., 536 MacArthur Blvd., Pocasset, MA 02559). The micro-controller provided the interface to the Series 2000 Control Board, with operational software written for the TFX-11 micro-controller initiating scans, controlling the pen scan sequence, the antenna scan sequence, and the collection of tag ID information during the scan. At the end of the scan, the ID information was transferred from the TFX-11 micro-controller to the PC host computer. The micro-controller waited until the next scan was initiated.

\subsection{Site installation}

The swine system had six pens; each had one feeder designed for 5 animals to eat at a time. The swine system was designed with only one micro-controller controlling 30 antennas and transferring the data within a $20-$ s scan time.

Existing stainless steel pig feeders were used at the swine facility. A multiplexer and a series of five antennas were mounted on a single sheet of PVC ( $1.18 \mathrm{~m}$ wide $\times .0 .65 \mathrm{~m}$ tall $\times 5 \mathrm{~mm}$ thick $)$. This PVC sheet, with the equipment mounted, was then slid inside a PVC panel $(1.2 \mathrm{~m}$ wide $\times 0.7 \mathrm{~m}$ tall $\times 0.04 \mathrm{~m}$ thick), shown in Fig. 2. A single water-tight connector was added to the back of the panel to run the coaxial cable and the multi-strand wire for control and data collection. This PVC panel was installed on the front of the feeder using an aluminum channel along the bottom edge of the panel for support and an aluminum flange to hold the top edge of the panel. The panels were installed on the existing feeders with a total of seven $2 \mathrm{~mm}$ screws to hold the flanges and a single $2.4-\mathrm{cm}$ hole to run the wires through the feeder and into the panel (Fig. 2). Tests with EID tags demonstrated sufficient range and sensitivity for the pig feeder system.

\subsection{Animals}

The facility used in this study was divided into eight pens (six grow-out pens and two sick pens). The instrumentation was installed in the six grow-out pens; these pens are designed to hold 40 pigs pen $^{-1}$. Since the instrumentation was installed in the building (Fall 2008), a total of four groups of pigs, approximately 240 each period, have been raised in the facility (Fall, 2008 through Fall 2010). The pigs initially weighed $24.6 \pm 5.4 \mathrm{~kg}$ (mean \pm standard deviations) and left the facility weighing $101.4 \pm 13.8 \mathrm{~kg}$. Three of the four periods were stocked with mixed sex (barrows and gilts) grow-finish pigs. The fourth period was stocked with 5 pens of gilts, saved for breeding, and 1 pen of barrows. The pigs had ad libitum access to feed and water and were checked for health concerns at least once a day.

Before the pigs were moved to the facility, a half duplex ID tag was inserted in the right ear of each pig. Data were checked on a weekly basis to ensure that all the tags were still installed and working properly. Animals without any recorded feeding events were checked for health issues and missing or malfunctioning tags.

For three of the four periods, the animals were weighed at 14 weeks, 22 weeks, and prior to slaughter. For the fourth period, the animals were weighed at 22 weeks. Gains were calculated using a linear regression to determine the slope of the weights and weigh days. Gains were not calculated on the 4th group of pigs. For the purposes of statistical analysis, gain categories were assigned to high, normal and low gain. The average daily gains for these pigs appeared to be normally distributed. Therefore, levels were set based on the available data, the top $12 \%$ of the pigs were considered "high" (average daily gain, ADG, $\geqslant 0.94 \mathrm{~kg} \mathrm{day}^{-1}$ ) and the bottom $15 \%$ were considered "low" (ADG $\left.<0.7 \mathrm{~kg} \mathrm{day}^{-1}\right)$, and all other pigs were considered in the normal group.

\subsection{Data}

The data (RFID reads on all 30 antennas every $20 \mathrm{~s}$ ) were collected and stored in separate files every day. The computer was located in the swine facility, and was connected wirelessly to the Internet to allow download and backup at least 3 times a week. The data were loaded on the database and total RFID

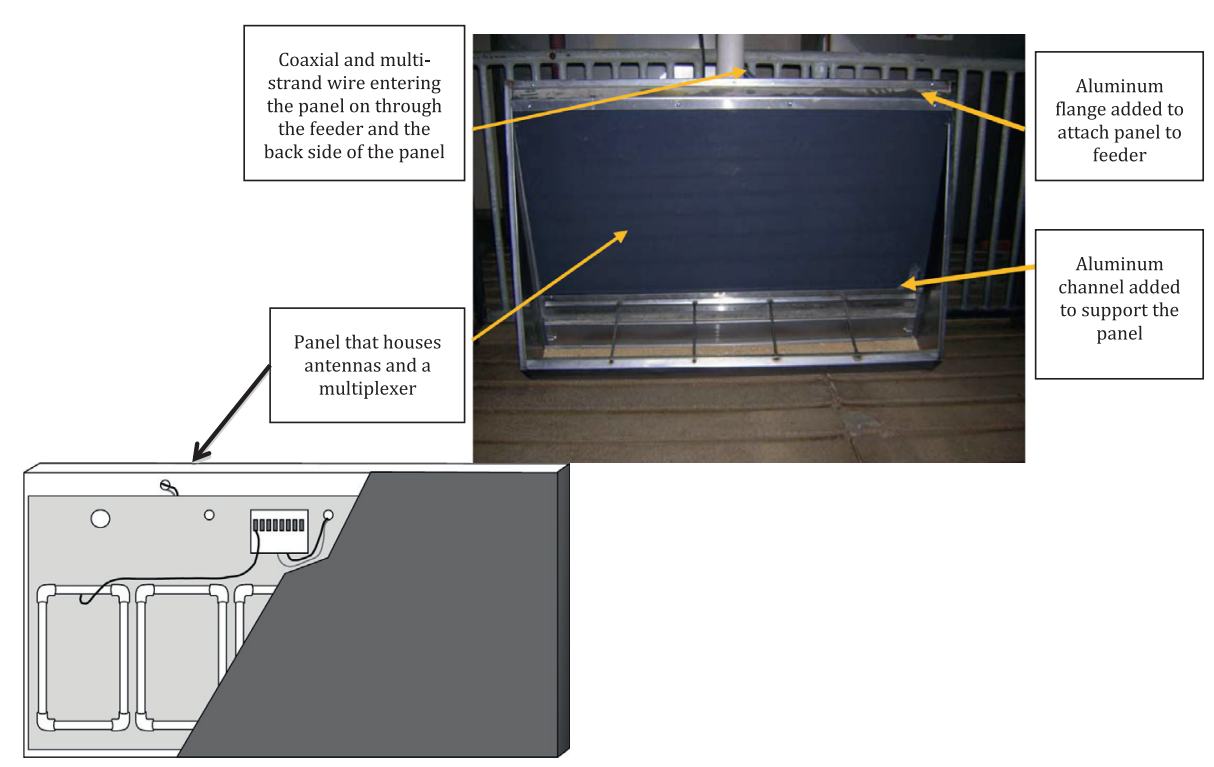

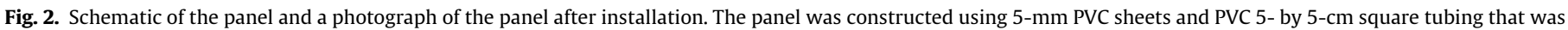

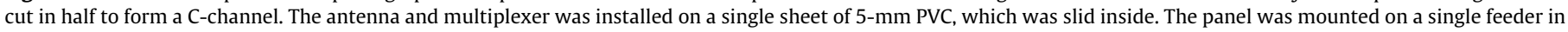
each of six pens. 
readings per day per animal were summarized. The total "RFID readings per day per animal" was simply divided by three to convert the readings into total time spent eating (minutes), this was done because readings were taken every $20 \mathrm{~s}$ (or three times a minute). Meal data on an animal basis (total number of meals per day, average length of meals) were also calculated, but not used in the analysis for this manuscript.

Four different data analyses were completed using the general linear model procedure in $\mathrm{SAS}^{\circledR}$. The first analysis evaluated the effects of days on feed (age of the animals); the model statement included effects of period and days on feed. The second analysis investigated the effects of weight gain on feeding behavior, so the model statement included the effects of period, days on feed, weight gain category (high, low, or normal) and the interaction effect of days on feed and weight gain category. The third analysis investigated the effects of sex on feeding behavior. The model statement included effects of period, days on feed, sex (barrows and gilts), and the interaction of days on feed and sex. These two analyses (weight gain and sex) were completed in periods 1 through 3 , as period 4 contained mainly gilts raised for breeding.

The fourth analysis evaluated the effects of health on time at the feeder. The model statement included effects of period, days on feed, and diagnosis. No interaction term was added. The only diagnosis that was analyzed was pneumonia, due to the lack of numbers on the other health related issues.

Differences were determined significant at the $P=0.05$ level. Least square means were used to determine the differences in treatments and the interaction terms.

\section{Results and discussion}

The pigs were moved into the facility at approximately 65 days of age where they remained on feed for approximately 112 days or until approximately 177 days of age - this ranged between 98 and 129 days on feed. The number of pigs in each pen varied from day to day as some of the pigs being treated because pigs with severe health issues were moved out of the pen during their treatment and a few tags were lost and replaced during the experiment.

\subsection{System performance}

The system worked well during the experiment. There were a few issues that incurred during the study. The first problem that occurred was the computer system automatically rebooting and the data collection system not restarting. This was difficult to problem solve, but was finally determined that they system automatically rebooted the computer after the automatic updates operating system were installed. This problem occurred during the second study, after the computer was added to the wireless network. Turning off automatic updates solved the problem. The second problem that occurred was EID tags being lost. Generally, the loss of EID tags was under 4\%. However, there were two occasions that the loss of tags became excessive. A single pen in two different studies accounted for a total of $56 \%$ of all the lost tags. Only 5 pigs out of 899 total were retagged more than one time. The last problem that occurred was a human error, during cleaning the feeders were tipped over and the cabling was pulled too hard and was disconnected. However, it does highlight the issue that cabling needs to be protected from the pigs as well.

\subsection{Overall feeding time}

The total time spent eating was affected by days on feed and period $(P<0.001)$. The average total time spent eating for a pig in the facility started at about $24 \mathrm{~min} \mathrm{day}^{-1}$ and increased steadily until a plateau was reached between 30-42 days on feed (approximately 95-107 days of age). The plateau was determined by using lsmeans procedure, $(P<0.05)$. The rate of increase from day 0 through day 42 was 1.28 min day $^{-1}$. After day 42 , the time spent at the feeder stabilized at approximately 76.7 min day $^{-1}$ until the pigs were removed from the pens in different slaughter groups. As pigs were removed from the pen, the remaining pigs spent more time at the feeder (Fig. 3). Using a feed intake system (FIRE, Osborne Industries), Hyun et al. (1997) reported a similar amount of time spent at the feeder (approximately $75 \mathrm{~min} \mathrm{day}^{-1} \mathrm{pig}^{-1}$ ). However, this was an average for the entire experiment (pigs ranging in weight from 24 to $89 \mathrm{~kg}$ ). Thus, Hyun's results are slightly higher that observed in this experiment.

\subsection{Effects of sex}

When the differences between sexes were analyzed, effects of period, days on feed, sex, and the interaction of days on feed and sex were all significant $(P<0.001)$. Barrows and gilts were fed the same diets in mixed sex pens. Barrows spent significantly more time at the feeder between day 26 and day 93 than the gilts. They reached a plateau at about $85 \mathrm{minday}^{-1} \mathrm{pig}^{-1}$, while the gilts reached a plateau at about $71 \mathrm{minday}^{-1} \mathrm{pig}^{-1}$ (Fig. 4). Hyun et al. (1997) reported no difference in time spent at the feeder, nor feed intake between barrows and gilts. However, differences in feed intake between barrows and gilts have been reported in the literature (Campbell and Taverner, 1988; Fuller et al., 1995). Hyun et al. (1997) suggested that the possible reason for not seeing a difference in their study was the feeding stations were affecting feeding behavior and intake. These data suggest that in a typical industry setting, where pigs are fed in mixed sexed pens, barrows would spend more time at the feeder.

\subsection{Effects of growth rate}

The highest gaining pigs in a pen are most likely the pigs that eat the most feed. When time spent at the feeder was analyzed, period, days on feed, gain category, and the interaction of gain category and days on feed were highly significant $(P<0.001)$. The pigs classified as high gaining pigs (gain $\geqslant 0.94 \mathrm{~kg} \mathrm{day}^{-1} ; N=63$ pigs) had the highest average time spent at the feeder $\left(79.1 \pm 0.45\right.$ min day $\left.^{-1}\right)$, followed by the normal pigs $\left(0.7 \mathrm{~kg} \mathrm{day}^{-1}<\right.$ gain $<0.94 \mathrm{~kg} \mathrm{day}^{-1}$; $71.0 \pm 0.15$ min $^{2} \mathrm{day}^{-1} ; \quad N=510$ ), and the low gaining pigs

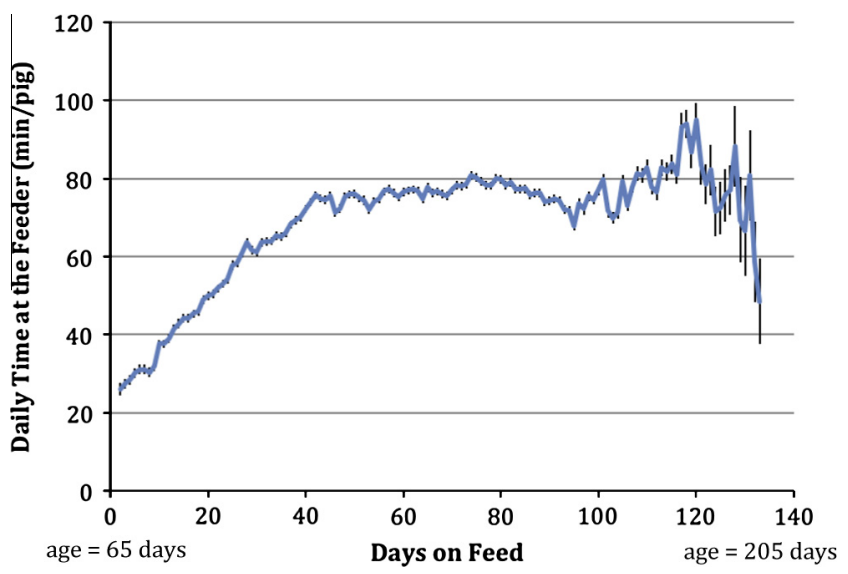

Fig. 3. Average time spent at the feeder $\left(\min\right.$ day $\left.^{-1} \mathrm{pig}^{-1}\right)$ as the pigs aged, error bars represent SEM. Day 0 on the graph depicts the day the pigs were moved into the facility (at approximately 65 days of age). Number of pigs varied on a daily basis, due to sick pigs being moved out and pigs being marketed. This analysis utilized three groups of pigs, a total of 741 pigs (groups 1 and 2-252 pigs; group 3237). 


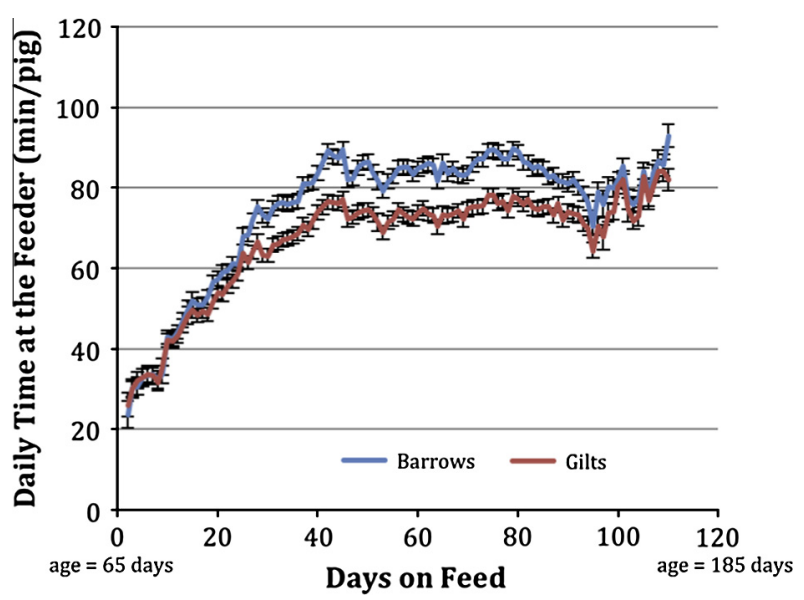

Fig. 4. Average time spent at the feeder $\left(\mathrm{min} \mathrm{day}^{-1} \mathrm{pig}^{-1}\right)$ throughout the grow-out period for barrows and gilts, error bars represent SEM. Day 0 on the graph depicts the day the pigs were moved into the facility (approximately 65 days of age). Number of pigs varied on a daily basis, due to sick pigs being moved out and pigs being marketed; average number of pigs during the first three periods was 102 barrows and 103 gilts. Data from the first three groups of pigs were utilized in the analysis (total number of pigs 741 pigs, 367 barrows; 374 gilts).

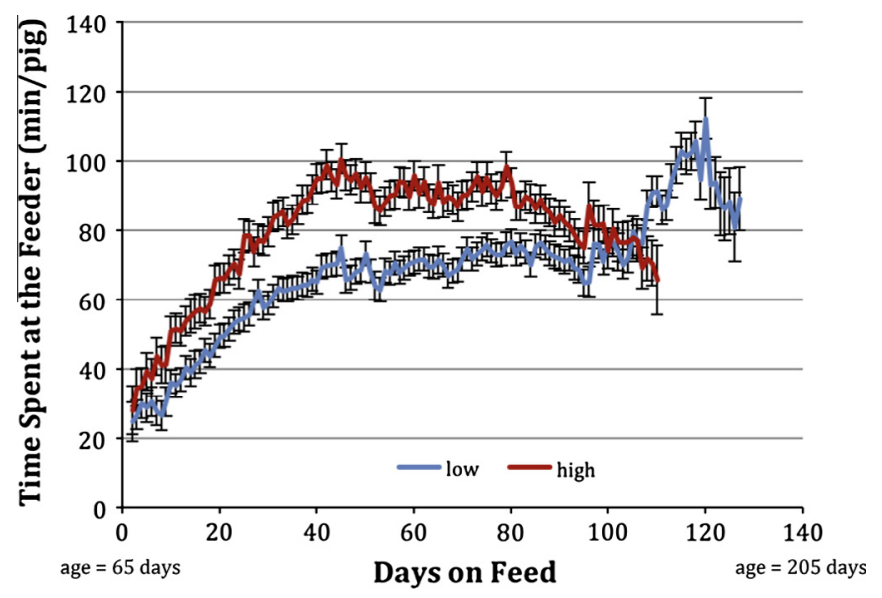

Fig. 5. Average time spent at the feeder $\left(\min _{\mathrm{day}}{ }^{-1} \mathrm{pig}^{-1}\right)$ throughout the grow-out period for high and low gaining pigs, error bars represent SEM. Day 0 on the graph depicts the day the pigs were moved into the facility (approximately 65 days of age). It is interesting to note the increase in the time spent at the feeder in the low gaining pigs after the high gaining pigs were removed. Number of pigs varied on a daily basis, due to sick pigs being moved out and pigs being marketed; average number of pigs in the high category was 54 (63 Maximum), low 80 (97 Maximum). Data from the first three groups of pigs were utilized in the analysis (total number of pigs 741 pigs).

(gains $<0.7 \mathrm{~kg} \mathrm{day}^{-1}$ ) had the lowest average time at the feeder (63.6 \pm 0.35 min day $\left.^{-1} ; N=63\right)(P<0.001$ for all differences).

Fig. 5 illustrates the changes in time spent at the feeder over the grow-out period for the high and the low groups. It was noted that the low gain group quickly separated from the high group (by day 7). Interestingly, after the high group was marketed the low gain group's time at the feeder quickly increased. This increased feeding activity was possibly due the social interaction of the pigs. This illustrates the importance of social interaction in a production setting, an aspect that is most often overlooked.

\subsection{Impacts of disease}

Out of 960 pigs, 458 pigs were treated for illness at least once. Due to the low frequency of many of the health concerns, only pneumonia was analyzed. Three hundred seventy-nine pigs were treated for pneumonia over the course of the study. The analysis for health concerns revealed that time spent at the feeder was impacted by period, days on feed, and diagnosis $(P<0.001)$. The pigs that were treated spent less time at the feeder than those who were never treated (treated $64.1 \pm 0.2 \mathrm{~min}$, non-treated $69.4 \pm 0.2 \mathrm{~min} ; P=0.0189$ ).

While this information is important in developing tools for producers to use to identify animals affected by a disease, the information that is needed is "What happened immediately preceding diagnosis and following treatment?" Fig. 6 illustrates the average response from a group of 240 pigs during a pneumonia outbreak where the animals in the building were all treated with antibiotics. In analyzing this graph it can be noted that time spent feeding started to decrease 2 days before the animals were treated. It can also be noted that the pigs responded to the treatment fairly quickly and were back to feeding levels equal to pre-treatment levels by 4 days post treatment.

However, the extremes are always lost in an average, so Fig. 7 illustrates two extreme feeding behaviors during that same outbreak. The two pigs were selected from the same litter to reduce the impact of genetics. One of the pigs (200909602) was obviously not impacted by disease, while the second animal (200909605) is very much impacted by the disease.

So, the question arises, "How many animals were impacted during this outbreak?" To answer that question, pigs were classified in three groups (not affected, affected, and unknown). The "affected" group was defined as pigs that spent less than $33 \mathrm{~min}$ at the feeder, the "not affected" group was defined as pigs that spent more than 66 min at the feeder, and the unknown group was composed of those who were intermediate. The time values of $33 \mathrm{~min}$ (100 reading day ${ }^{-1}$ ) and 66 min (200 reading day ${ }^{-1}$ ) were chosen somewhat arbitrarily to demonstrate the effect. These numbers were based on the minimum individual pig average and the average minimum time spent at the feeder between 42 and 100 days of the first three studies, which were $67 \mathrm{~min}$, and the $34 \mathrm{~min}$, respectively. The number of pigs in each group changed on a daily basis before and after the outbreak (Fig. 8).

Investigating the data collected over the 11-day time period presented in Fig. 8 reveals some interesting details. There were 160 animals out of the 240 that had at least 1 day with less than $33 \mathrm{~min}$ at the feeder. Of those 160 pigs, 104 spent less than 7 min eating and 50 animals that spent no time at the feeder for at least 1 day. The number of pigs in each threshold for a minimum number of days (1-11 days) is presented in Table 1 . Although this exact threshold cannot be determined, it appears that there are a certain percentage of pigs that spend approximately 30 min eating on a

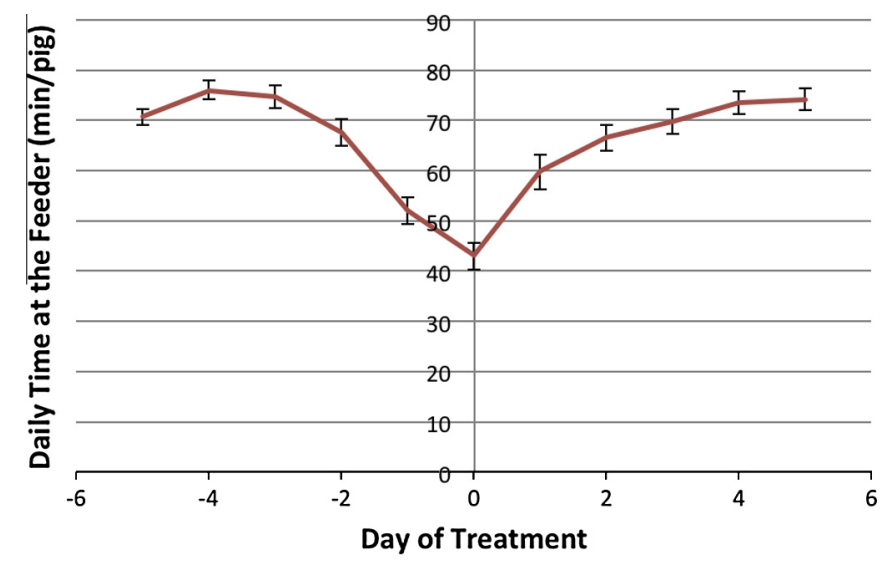

Fig. 6. Average time spent at the feeder during a major pneumonia outbreak, error bars represent SEM. All 240 pigs in the building were treated with antibiotics on day 0 ; days preceding and following day 0 are added for informational purposes. 


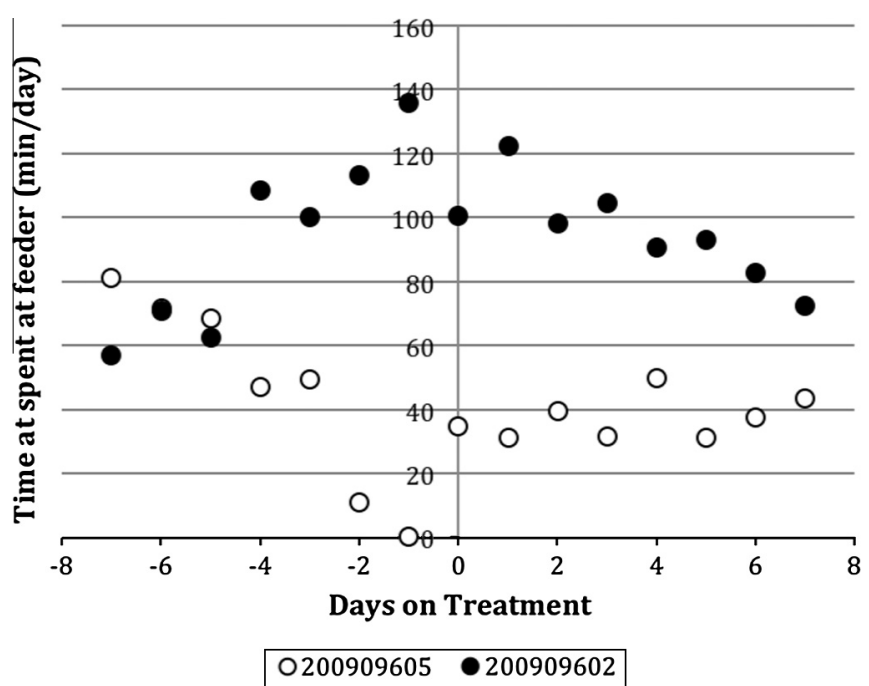

Fig. 7. Time spent at the feeder for two pigs with different responses during a major pneumonia outbreak. Pig Number 200909602 and Pig Number 200909605 are littermates and were housed in the same pen.

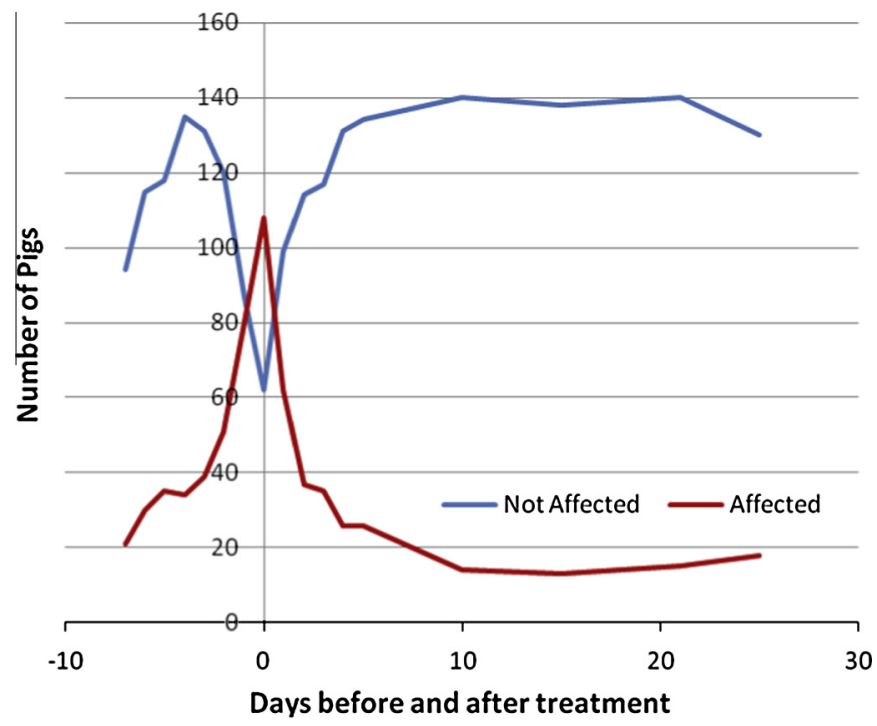

Fig. 8. Daily count of pigs classified as affected (pigs that spent $<33 \mathrm{~min}$ at the feeder) and pigs classified as not affected (pigs that spent $>66 \mathrm{~min}$ at the feeder) preceding and following a major pneumonia outbreak in the facility.

Table 1

Count of pigs below threshold times during an 11 day period surrounding a pneumonia outbreak, pigs within the facility were treated in the middle of the 11 days with an oral antibiotic. Counts signify the number of pigs that spent less than the threshold time at the feeder (33, 7, $0 \mathrm{~min}$ ), for a minimum of 1-11 days.

\begin{tabular}{lrrrrrrr}
\hline & 1 Day & 2 Days & 3 Days & 4 Days & 5 Days & 6 Days & 11 days \\
\hline$<33 \min$ & $160^{\mathrm{a}}$ & 123 & 82 & 58 & 42 & 33 & 13 \\
$<7 \mathrm{~min}$ & 104 & 49 & 20 & 20 & 20 & 0 & 0 \\
0 min & 50 & 8 & 2 & 2 & 2 & 0 & 0 \\
\hline
\end{tabular}

a 160 pigs had at least 1 day in which they spent less that $33 \mathrm{~min}$ at the feeder.

regular basis, as 13 pigs spent all 11 days of this time period at this level. During this same period, it was noted that 40 out of the 240 pigs spent the minimum amount of time eating on the same day as the antibiotic treatment was applied (day 0 in Fig. 8). Of those 40 pigs, 32 pigs returned to the quickly returned to their previous "time at the feeder" after the treatment was removed. Tracking the daily feeding time of individual animals may lead to earlier diagnosis, quicker treatment, and better tracking of recovery.

While using the standard statistical models on these data provided some new and useful information, generally the information is in support of literature data. However, the current analysis has only considered a small amount of the information that is available. The data collected by this system and other feed intake systems that are collecting vast amounts of data that provide a considerable amount of information about each individual animal on at least a daily basis if not on an hourly basis. Being able to track changes in an individual animal's feeding behavior or simply time spent eating could provide a wealth of information. However, the systems to provide this type of analysis have not been developed.

Currently, there are two limitations utilizing the equipment and developing software to track feeding behavior and provide information to a producer: the knowledge of the animal system, and analysis methods that can work in tandem with the data collecting or data-basing software. Questions to be addressed concerning the knowledge of the animal system include:

- What feeding level is normal and abnormal?

- What are the boundaries on a normal feeding level?

- Using time spent eating, can individual animal problems be identified, proper solution (removal, medication, etc.) applied, and recovery monitored?

While scientists have determined mean feed intake, or in this case, the mean time spent at the feeder, two questions remain: what are the boundaries of the normal range? and what is the normal day to day variation associated with a single animal? Future research will be focused on answering these questions.

\section{Conclusions}

Equipment and data collection software was designed to collect feeding behavior using RFID technology was developed and installed in a swine facility. The data were collected on 4 groups of pigs for a total of 960 individual animals. Differences in time spent at the feeder was found to be related to age, sex, gain classification, and health.

- Time spent at the feeder changed during the grow-out phase. The pigs increased their time at the feeders until day 30-42 (95-105 days of age) when their time at the feeders reached a plateau at 76.7 min day $^{-1}$.

- The barrows spent more time at the feeders than the gilts (85 min pig $^{-1}$ day $^{-1}$ compared to $71 \mathrm{~min} \mathrm{pig}^{-1} \mathrm{day}^{-1}$ ).

- The data from the system revealed that the pigs in the high weight gain class spent more time at the feeder than either the normal gaining pigs or the low gaining pigs. The high gaining pigs spent about 79 min day ${ }^{-1}$ at the feeder compared to 71 min day $^{-1}$ for the normal gaining pigs and 64 min day $^{-1}$ for the low gaining pigs. It was noted that the low gain group quickly became significantly different from the high gain group. Interestingly, the low gain group's time at the feeder increased dramatically after the high gain group was removed from the pen (as they reached market weight). This indicated that some of the differences between the two groups were related to the social interaction of the pigs.

- The amount of time spent at the feeder decreased during a pneumonia outbreak. Overall, pigs treated for pneumonia spent less time at the feeder than those not diagnosed with pneumonia. We determined that a system to monitor time spent at the feeder could provide useful information for determining the impact that a disease has on an individual animal. 
While this study demonstrates the potential of utilizing feeding behavior or time spent eating to manage pigs in a commercial setting, the technology and understanding need to be developed further. Before one could manage animals utilizing this information, a better understanding of the normal ranges, expected day to day variations for a single animal, and explainable changes (effects of dietary changes, and temperature) need to be developed. In addition, techniques need to be developed to forecast individual feeding behavior (or time spent eating), and methods to detect significant and meaningful deviations from the forecasted amount. Regardless of the work that needs to be completed, time spent eating does appear to have potential of changing the method of managing animals from an strictly an observational activity to a largely a data driven one.

\section{References}

Adijaoude, J.A., Morand-Fehr, P., Tessier, J., Schmidely, P.H., Sauvant, D., 2000. Diet effect on the daily feeding behaviour, frequency and characteristics of meals in dairy goats. Livest. Prod. Sci. 64, 29-37.

Andree, H., Huegle, T.U., 2001. Effect of Single Animal Feeding Stations and Group Size on Growing Performance of Group Housed Fattening Pigs. American Society of Agricultural and Biological Engineering Meeting Paper No. 014026. ASAE, St. Joseph, MI.

Bach, A., Iglesias, C., Busto, I., 2004. Technical note: a computerized system for monitoring feeding behavior and individual feed intake of dairy cattle. J. Dairy Sci. 87, 4207-4209.

Basarab, J.A., Price, M.A., Aalhus, J.L., Okine, E.K., Snelling, W.M., Lyle, K.L., 2003. Residual feed intake and body composition in young growing cattle. Can. J. Anim. Sci. 83, 189-204.

Bigelow, J.A., Houpt, T.R., 1988. Feeding and drinking patterns in young pigs. Physiol. Behav. 43, 99-109.

Campbell, R.G., Taverner, M.R., 1988. Genotype and sex effects on the relationship between energy intake and protein deposition in growing pigs. J. Anim. Sci. 66, 676-686.

Chapinal, N., Veira, D.M., Weary, D.M., von Keyserlingk, M.A.G., 2007. Technical note: validation of a system for monitoring individual feeding and drinking behavior and intake in group-housed cattle. J. Dairy Sci. 90, 5732-5736.

Chapinal, N., Ruiz-de-la-Torre, J.L., Cerisuelo, A., Baucells, M.D., Gasa, J., Manteca, X., 2008. Feeder use patterns in group-housed pregnant sows fed with an unprotected electronic sow feeder (Fitmix). J. Appl. Anim. Welfare Sci. 11, 319-336.

Fuller, M.F., Franklin, M.F., McWillian, R., Pennie, K., 1995. The responses of growing pigs, of different sex and genotype, to dietary energy and protein. Anim. Sci. 60, 291.
Gates, R.S., Xin, H., 2008. Extracting poultry behaviour from time-series weigh scale records. Comput. Electron. Agric. 62, 8-14.

Gipson, T.A., Goetsch, A.L., Detweiler, G., Merkel, R.C., Sahlu, T., 2006. Effects of the number of yearling Boer crossbred wethers per automated feeding system unit on feed intake, feeding behavior and growth performance. Small Rumin. Res. 65, 161-169.

Gipson, T.A., Goetsch, A.L., Detweiler, G., Sahlu, T., 2007. Effects of feeding method, diet nutritive value and physical form and genotype on feed intake, feeding behavior and growth performance by meat goats. Small Rumin. Res. 71, 170178.

Goetsch, A.L., Gipson, T.A., Askar, A.R., Puchala, R., 2010. Invited review: feeding behavior of goats. J. Anim. Sci. 88, 361-373.

Griffin, D., 2001. How health status and environment influence the feeding behavior of feedlot cattle. In: 3rd Annual Intermountain Nutrition Conference, Utah State University, Logan, Utah, pp. 117-124.

Hyun, Y., Ellis, M., 2002. Effect of group size and feeder type on growth performance and feeding patterns in finishing pigs. J. Anim. Sci. 80, 568-574.

Hyun, Y., Ellis, M., McKeith, F.K., Wilson, E.R., 1997. Feed intake pattern of grouphoused growing-finishing pigs monitored using a computerized feed intake recording system. J. Anim. Sci. 75, 1443-1451.

Kelly, A.K., McGee, M., Crews Jr., D.H., Fahey, A.G., Wylie, A.R., Kenny, D.A., 2010 Effect of divergence in residual feed intake on feeding behavior, blood metabolic variables, and body composition traits in growing beef heifers. J. Anim. Sci. 88, 109-123.

Korthals, R.L., 2000. Evaluation of space requirements for swine finishing feeders Trans. Am. Soc. Agric. Biol. Eng. 43, 395-398.

Morgan, C.A., Emmans, G.C., Tolkamp, B.J., Kyriazakis, I., 2000. Analysis of the feeding behavior of pigs using different models. Physiol. Behav. 68, 395-403.

Nienaber, J.A., McDonald, T.P., Hahn, G.L., Chen, Y.R., 1990. Eating dynamics of growing-finishing swine. Trans. ASAE 33, 2011-2018.

Nienaber, J.A., McDonald, T.P., Hahn, G.L., Chen, Y.R., 1991. Group feeding behavior of swine. Trans. ASAE 34, 289-294.

Nienaber, J.A., Hahn, G.L., 2000. Feeding Behavior and Energetics of GrowingFinishing Swine as Influenced by Environmental Temperature. ASABE Meeting Paper No. 87-4512. American Society of Agricultural Engineers, St. Joseph, MI 49085.

Puma, M.C., Xin, H., Gates, R.S., Burnham, D.J., 2001. An instrumentation system for studying feeding and drinking behavior of individual poultry. Appl. Eng. Agric 17, 365-374.

Soltysiak, T., Ogalski, Z., 2010. The effects of social hierarchy in a dairy cattle herd on milk yield. Polish J. Natural Sci. 25, 22-30.

Val-Laillet, D., Veira, D.M., von Keyserlingk, M.A.G., 2008. Short communication: dominance in free-stall-housed dairy cattle is dependent upon resource. J. Dairy Sci. 91, 3922-3926.

Walker, S.L., Smith, R.F., Routly, J.E., Jones, D.N., Morris, M.J., Dobson, H., 2008 Lameness, activity time-budgets, and estrus expression in dairy cattle. J. Dairy Sci. 91, 4552-4559. 